\title{
The Establishment of Vesicular-Arbuscular Mycorrhiza under Aseptic Conditions
}

\author{
BY BARBARA MOSSE \\ Soil Microbiology Department, Rothamsted Experimental Station, \\ Harpenden, Hertfordshire
}

(Received 26 July 1961)

\section{SUMMARY}

The establishment of vesicular-arbuscular mycorrhizal infections by inoculation with germinated resting spores of an Endogone sp. was investigated under microbiologically controlled conditions; pure twomembered cultures were obtained for the first time.

Seedlings were grown in a nitrogen-deficient inorganic salt medium; in these conditions the fungus failed to form an appressorium and to penetrate the plant roots unless a Pseudomonas sp. was also added. Adding soluble nitrogen to the medium completely inhibited root penetration, even in the presence of the bacteria. Various sterile filtrates could be used to replace the bacterial inoculum but these substitutes induced only few infections per plant.

Mycorrhizal roots grew more vigorously than non-mycorrhizal roots of the same seedling. They were longer and more profusely branched. At first mycorrhizal infections were predominantly arbuscular, but many prominent vesicles developed as the seedlings declined, and then the fungus grew out of infected roots and colonized the agar. The fungus could not be subcultured without a living host.

The possible interpretation of these results is considered with reference to the specialized nutritional conditions under which test plants were grown.

\section{INTRODUCTION}

For a critical study of the effects of vesicular-arbuscular mycorrhiza on plant growth, typical infections must be produced under controlled microbiological conditions. Some progress has been made towards this with the isolation of four different fungi able to cause such infections. Two of these, an unidentified species at present called Rhizophagus sp. (Barrett, 1947, 1958), and a strain of Pythium ultimum (Hawker, Harrison, Nicholls \& Ham, 1957) are available in pure culture, whereas the others, both Endogme spp. (Mosse, 1958, 1956, 1959a; Gerdemann, 1955) were obtained as soil-borne spores. In successful inoculation experiments, test plants were grown in sterilized soil or in a liquid medium in open containers. Repeated attempts to produce normal vesicular-arbuscular mycorrhiza in an angiosperm species under aseptic conditions have so far failed (Hawker et al. 1957; Barrett, 1959; Mosse, $1959 b$ ). Hepden (1960) appears to have had some success with fern sporophytes grown in sand culture but the absence of other 
microbial contaminants in the successfully inoculated plants was not establishcd. All the evidence suggests that very specialized conditions, or perhaps even the presence of some other micro-organism, are needed to establish vesicular-arbuscular infections in culture. The inoculation experiments described below confirm this suggestion. The excised, surface-stcrilized, resting spores of a sporocarp-forming Endogone sp. were used as inoculum. Under aseptic conditions the germ tubes of this fungus did not penetrate the roots of test plants, but the presence of certain soil bacteria enabled them to do so when the plants were deficient in nitrogen. Some, but much less root penetration was also induced by 'Pectinol', a commercial pectinase enzyme preparation (Rohm and Haas Co., Philadelphia, Pennsylvania, U.S.A.), by ethylenediaminetetra-acetic acid (FDTA), a chelating agent, and by cell-free filtrates of culture solutions in which plants and bacteria had been grown together. This makes it possible to synthesize vesicular-arbuscular mycorrhiza in pure twomembered cultures.

\section{METHODS}

In experiments of this kind three factors require consideration: (1) the provision of sterile test plants; (2) the composition of the medium in which both plant and fungus must grow; (3) the preparation of a sterile inoculum.

Test plants. Seedlings of Trifolium parviflorum were used for the systematic inoculation experiments, and $T$. glomeratum, $T$. pratense, $T$. subterraneum, Dactylis glomerata, wheat (Triticum vulgare), cucumber (Cucumis sativus) and onion (Allium cepa) seedlings were also used to test the general applicability of the results.

Clover seeds were sterilized in concentrated sulphuric acid, chilled, and germinated on agar plates, by a technique described by Nutman (1949). All other seeds were sterilized for $15 \mathrm{~min}$. in $10 \mathrm{ppm}$ ethyl mercury phosphate. They were then rinsed in fifteen changes of sterile water, and were incubated at $15^{\circ}$ on $0.75 \%$ agar in water $(w / v)$ again. After germination, seedlings were transferred to agar slopes in stcrile test tubes, which were kept in a greenhouse.

Culture medium. All test plants were grown in a nitrogen-deficient inorganic salt medium formulated by Jensen (1942) and used extensively in nodulation studies. It contained g./l. of distilled water: $1, \mathrm{CaIIPO}_{4} ; 0.2, \mathrm{~K}_{2} \mathrm{IPO}_{4} ; 0.2, \mathrm{NaCl} ; 0.2$, $\mathrm{MgSO}_{4} .7 \mathrm{H}_{2} \mathrm{O} ; 0 \cdot \mathrm{I}, \mathrm{FeCl}_{3} ; 7 \cdot 5$, shredded agar. The medium was adjusted to $\mathrm{pH} 6 \cdot 3$ before autoclaving at $120^{\circ}$ for $20 \mathrm{~min}$.

Inoculum. An uncontaminated inoculum of germinated resting spores of an Endogone sp. was obtained as previously described (Hosse, 1959a). Spores excised from the sporocarps were sterilized in two changes of a freshly prepared $2 \%(\mathrm{w} / \mathrm{v})$ solution of Chloramine T containing $200 \mathrm{ppm}$ streptomycin. After washing, 20-30 sterilized sporcs were transferred to a small cellophan disk, which was placed on a large piece of sterile cellophan spread over a soil agar plate containing $0 \cdot 2 \mathrm{~g}$. soil dispersed in $5 \mathrm{ml} .0 .75 \%(\mathrm{w} / \mathrm{v})$ agar in water and containing $0.001 \%$ crystal violet. After incubation for 5 to 6 days at $20^{\circ}$ the small cellophan disks, now covered with a network of anastomosing germ tubes, were tested for freedom from bacterial contaminants by incubating them on nutrient agar for $24 \mathrm{hr}$. They were also examined microscopically and any with fungal contaminants were discarded. More than $90 \%$ of the disks carried a pure inoculum, which was introduced, without disturbing the mycelial network, by placing the small cellophan disks, with the spore-bearing surface uppermost, near to an actively growing seedling root. 


\section{RESULTS}

\section{Conditions necessary for the establishment of infections}

The preparation of the inoculum is laborious, and as the results looked for were qualitative rather than quantitative, a limited replication was considered to be sufficient. Fach inoculation test was repeated at least three times, often on two or more separate occasions. In all over 800 inoculations were made, yielding reasonably consistent results. 'The most variable factor was a seasonal difference in the growth rate of test secdlings which affected the time required for the establishment of infections. Infection was favoured by temperature and light conditions which promoted vigorous seedling growth. A 12-hr. day length was maintained by supplementary fluorescent lighting during the winter, and temperatures of $20-25^{\circ}$ during part of this period assisted infection. Except for four strains of subterranean clover, all the plant species tested became mycorrhizal (Table 1), under certain specialized conditions which are discussed below.

The bacterial factor. The inoculation of sterile seedlings with sterile germinated spores never produced a mycorrhizal infection. Altogether about 50 two-membered cultures of this kind were examined. The fungus did not penetrate the roots even when they were damaged mechanically. In the earliest experiments, however, in which the sterility of the inoculum had not been checked, a few test plants became mycorrhizal, and all these cultures also contained a bacterial contaminant, often a Pseudomonas sp. Two pscudomonad isolates (No. 1 and 2) were obtained in pure culture. Both grew well on beef-extract peptone yeast agar, on which No. 2 produced a strongly fluorescent pigment. Both pseudomonads induced the changes necessary for fungal penetration of the roots (Table 1), but neither directly affected the germination of Endogone spores or the growth of the germ tubes. Quite a small bacterial inoculum sufficed to mediate infections, and it was immaterial whether the pseudomonads were added together with the fungal inoculum or later. Mycorrhizal infections were also produced in liquid culture with the aid of a pseudomonad inoculum. No bacteria were found within mycorrhizal roots.

Table 1 shows that other bacteria also induced the changes leading to infection. Two strains of Pseudomonas marginalis, both with pectolytic activity, had this effect, but a nodule-forming strain of a Rhizobium sp. had not. This aspect of the problem was not further pursued, but experiments designed to replace the bacterial factor by cell-free extracts give some indication of ways in which the bacterial inoculum may act. Table 2 gives a summary of some of these experiments.

Of the various cell-free extracts tried, only porcelain-filtered suspensions of the bacteria in distilled water (Nxpt. 1 $b$, Table 2), and filtrates from dual cultures of plant and bacteria grown in a nitrogen-deficient liquid medium (Expt. $1 c$ and $d$, Table 2), led to the establishment of infections. It seemed that the active factor might be some enzyme produced by bacteria when lacking nitrogen; two crystalline proteolytic enzymes, pepsin and trypsin, were however without effect (Expt. 2, Table 2). The role of pectolytic enzymes in the penetration processes of many pathogenic micro-organisms (Wood, 1955), and of nodule bacteria (Fåhraeus \& Ljunggren, 1959; Ljunggren, 1961) suggested tests with Pectinol, a commercial enzyme preparation that is both pectolytic and cellulolytic (Jackson, 1959). The Pectinol, containing the active enzymes adsorbed on an inert carrier, was sus- 
pended in water, filtered to remove the insoluble carrier and then sterilized by filtration through a porcelain candle. At concentrations from 0.02 down to $0.0002 \%$ $(w / v)$ it was the most effective of the sterile filtrates. Concentrations of Pectinol higher than $0.02 \%$ were not more effective, and caused discoloration and stunting of the clover roots. On the assumption that the Pectinol acted as a mild macerating agent, tests were made with ethylenediaminetetra-acetic acid (EDTA) which has

Table 1. The effect of bacterial inoculation and soluble nitrogen on the establishment of Endogone infections in sterile seedlings

\begin{tabular}{|c|c|c|c|}
\hline Test plant & Hacterial inoculum & $\begin{array}{l}\text { Additional nitrogen } \\
\text { source }\end{array}$ & $\begin{array}{l}\text { No. of plants } \\
\text { with vesicular- } \\
\text { arbuscular } \\
\text { infections }\end{array}$ \\
\hline Trifolium parviflorum & $\begin{array}{l}\text { None } \\
\text { Pseudomonas sp. }\end{array}$ & $\begin{array}{c}\text { None } \\
, "\end{array}$ & $\begin{array}{r}0 / 56 \\
30 / 30\end{array}$ \\
\hline $\begin{array}{l}\text { T. parviflorum } \\
\text { (in liquid culture) }\end{array}$ & Psetudomonas sp. & ", & $6 / 6$ \\
\hline \multirow[t]{6}{*}{ T. parviflorum } & $\begin{array}{l}\text { Pseudomoncs sp., } \\
\text { isolate } 2\end{array}$ & $"$ & $15 / 15$ \\
\hline & $\begin{array}{l}\text { P. marginalis, } \\
\text { No. 506* }\end{array}$ & $"$ & $5 / 5$ \\
\hline & $\begin{array}{l}\text { P. marginalis, } \\
\text { No. } 667^{*}\end{array}$ & $"$ & $3 / 3$ \\
\hline & $\begin{array}{l}\text { Chance contamina- } \\
\text { tion }\end{array}$ & $"$ & $60 / 81$ \\
\hline & Rhizobium sp. & $"$ & $0 / 8$ \\
\hline & Pseudomonas sp. & $\begin{array}{l}0.05 \% \mathrm{KNO}_{8} \\
0.05 \%\left(\mathrm{NH}_{4}\right)_{8} \mathrm{SO} \\
0.05 \% \text { urea } \\
0.05 \% \text { asparagine }\end{array}$ & $\begin{array}{l}0 / 8 \\
0 / 8 \\
1 / 6 \dagger \\
1 / 8 \dagger\end{array}$ \\
\hline$T \cdot$ pratense & $\begin{array}{l}\text { None } \\
\text { Pseudomonas sp. }\end{array}$ & $\begin{array}{c}\text { None } \\
\quad "\end{array}$ & $\begin{array}{l}0 / 5 \\
5 / 5\end{array}$ \\
\hline$T \cdot$ glomerafum & $\begin{array}{l}\text { None } \\
\text { Pseudomonas sp. }\end{array}$ & ", & $\begin{array}{l}0 / 8 \\
3 / 3\end{array}$ \\
\hline Dactylis glomerata & $\begin{array}{l}\text { None } \\
\text { Pseudomonas sp. }\end{array}$ & " & $\begin{array}{l}0 / 5 \\
6 / 10\end{array}$ \\
\hline Whest & $\begin{array}{l}\text { None } \\
\text { Pseudomonas sp. }\end{array}$ & ", & $\begin{array}{l}0 / 3 \\
8 / 10\end{array}$ \\
\hline Onion & $\begin{array}{l}\text { None } \\
\text { Preudomonas sp. }\end{array}$ & ", & $\begin{array}{l}0 / 3 \\
5 / 5\end{array}$ \\
\hline Cucumber & $\begin{array}{l}\text { None } \\
\text { Pseudomonas sp. }\end{array}$ & ", & $\begin{array}{c}0 / 5 \\
10 / 18\end{array}$ \\
\hline $\begin{array}{l}T \text {. subterraneum } \\
4 \text { strains }\end{array}$ & $\begin{array}{l}\text { None } \\
\text { Pseudomonos sp. }\end{array}$ & " & $\begin{array}{l}0 / 5 \\
0 / 5\end{array}$ \\
\hline
\end{tabular}

Pseudomonas sp. isolate 1 was used as bacterial inoculum unless otherwise stated.

* Supplied by Dr R. A. Ielliott, Plant Pathology Iaboratory, Harpenden, Hertfordshire.

t Infections developed after 10 weeks.

also been used in maceration (Humphries \& Wheeler, 1960; Ginzburg, 1961). At low concentrations ED'TA, although acting more slowly than Pectinol also assisted in the infection process of Endogone spores, but at concentrations higher than $0.0002 \%$ it did not, and damaged the roots (Expt. 4, Table 2). Tomlinson \& Webb (1960) 
reported a similar action of EDTA which enabled Erisyphe polygoni to infect turnip tissue treated with zinc sulphate. Various mixtures of Pectinol, FDTA, trypsin and pepsin were tried, but none proved more effective than Pectinol alone. Autoclaved Pectinol and autoclaved filtrates from dual cultures of plant and bacteria to which $0 \cdot 1 \%(\mathrm{w} / \mathrm{v})$ pectin had been added were also effective sometimes (Expt. 1d, 3, Table 2) but, as with EDTA, infections developed only slowly.

Table 2. The effect of sterile filtrates on the establishment of Endogone infections in Trifolium parviflorum

Substances tested

(1) Culture filtrates of Pseudo-

monas sp. (isolate 1)

(a) Grown for 2 days in

beef-extract yeast

peptone broth

(b) Grown in nutrient broth;

centrifuged and sus-

pended in distilled

water

(c) Grown with clover seedling for 2 weeks in Jensen's medium

(d) Grown with clover seed-

ling for 2 weeks in

Jensen's medium $+0 \cdot 1 \%(w / v)$ pectin

(2) Proteolytic enzymes
(a) trypsin
(b) pepsin

(8) Pectinol $100 \mathrm{D}$

(4) Ethylenediaminetetra-

acetic acid (EDTA)

neutralized with $\mathrm{NaOH}$

\section{Method of steriliza- tion}

Final
concentration
$(\%)$
No. of plants with vesicular-arbuscular infections

$\begin{array}{lll}\text { A } & 10 & 0 / 5 \\ \text { S } & 10 & 0 / 8 \\ \text { C } & 10 & 0 / 4 \\ \text { A } & 10 & 0 / 6 \\ \text { S } & 10 & 0 / 8 \\ \text { C } & 10 & 2 / 10 \\ \text { D } & 10 & 0 / 15 \\ \text { A } & 10 & 0 / 3 \\ \text { C } & 10 & 5 / 14 \\ \text { C } & 50 & 2 / 4 \\ \text { A } & 10 & 4 / 11^{*} \\ \text { C } & 10 & 8 / 15\end{array}$

\begin{tabular}{|c|c|c|c|}
\hline$C$ & $\begin{array}{l}\left\{\begin{array}{l}10^{-8} \\
10^{-1}\end{array}\right. \\
\left\{\begin{array}{l}10^{-a} \\
10^{-1}\end{array}\right.\end{array}$ & $\begin{array}{l}0 / 3 \\
0 / 2 \\
0 / 5 \\
0 / 2\end{array}$ & \\
\hline $\mathbf{C}$ & $\begin{array}{l}\left\{\begin{array}{c}0.1 \\
2 \times 10^{-3} \\
2 \times 10^{-3} \\
2 \times 10^{-4}\end{array}\right. \\
2 \times 10^{-2}\end{array}$ & $\left.\begin{array}{c}1 / 3 \\
12 / 16\end{array}\right\}$ & $\begin{array}{l}\text { some root } \\
\text { damage }\end{array}$ \\
\hline & $\left\{\begin{array}{l}2 \times 10^{-2} \\
2 \times 10^{-2} \\
2 \times 10^{-4} \\
2 \times 10^{-6}\end{array}\right.$ & $\left.\begin{array}{l}0 / 4 \\
0 / 5 \\
3 / 5^{*} \\
3 / 5^{*}\end{array}\right\}$ & $\begin{array}{l}\text { some root } \\
\text { damage } \\
\text { roots slightly } \\
\text { stunted }\end{array}$ \\
\hline
\end{tabular}

Methods of sterilization $\mathrm{A}=$ autoclaved at $120^{\circ}$ for 20 min.; $\mathrm{S}=$ Seitz filtered; $\mathrm{C}=$ filtered through porcelain candle; $\mathrm{D}=$ sonically disintegrated and filtered through porcelain candle.

* Infections developed slowly.

Although indistinguishable in anatomical details, infections established with the aid of a bacterial inoculum were always more widespread than those induced with sterile filtrates (Table 3). Adding larger amounts of filtrate than in Table $\mathbf{8}$ did not increase the number of infections; it is therefore possible that the active factor becomes adsorbed or otherwise inactivated during the experiment, or that the optimum concentration is low. It was thought that the number of infections might be related to plant size and photosynthetic area, which was increased as a result of adding the bacterial inoculum. Applying urea to the leaves, which increased plant 
size, did not however increase the number of infections, although it stimulated fungal growth in the agar once an infection had taken place, and there were more points of contact between the mycelium and the root system.

The effect of soluble nitrogen in the medium. In addition to the bacterial factor, the supply of nitrogen in the medium is important in the establishment of Endogone infections. The mineral salt medium used contains a very small amount of nitrate as impurity; $1.5 \mu \mathrm{g}$. in $10 \mathrm{ml}$. solution. A more important nitrogen source was the shredded agar which contributed $150 \mu \mathrm{g}$. total- $\mathrm{N}$ in $10 \mathrm{ml}$. of the medium; less than one quarter of this was directly available to the plant. The rest of this nitrogen in the agar was probably in the form of protein-like impurities (Spec. Rep. Soc. gen. Microbiol. 1956) some of which can be made available to the plant by microbial and enzyme action. In such a nitrogen-deficient medium the small-seeded clover species began to show symptoms of nitrogen deficiency after 2-3 wecks. To overcome this, potassium nitrate, ammonium sulphate, asparagine and urea were tried as additional nitrogen sources at $0.05 \%(w / v)$. Such additions improved plant growth, but completely inhibited the establishment of Endogone infections, even in the presence of bacteria (Table 1). A few infections developed after 10 weeks or more, when the plants were again showing symptoms of nitrogen starvation.

Table 3. The effect of bacterial inoculations and sterile filtrates on the intensity of mycorrhizal infection in sterile seedlings of Trifolium parviflorum inoculated with $a$ species of Endogone

Aid to infection

Pseudomonas sp., isolate 1

P. marginalis, No. 506

Chance contamination

Sterile filtrate from dual cul-

ture of plant and Pseudo-

monas sp., isolate 1

Pectinol

EI)TA

No. of plants
examined
10
5
20
10
12

3
Mean no. of mycorrhizal roots per plant

$5 \cdot 2$
$5 \cdot 0$
$4 \cdot 1$
$2 \cdot 3$

$1 \cdot 8$

$2 \cdot 0$

Mean no. of
entry points
per plant

$22 \cdot 0$

$20 \cdot 0$

$17 \cdot 0$

$\mathbf{2} \cdot 8$

$3 \cdot 7$

8.0

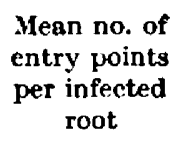

Mean no. of entry points per infected root

$4 \cdot 2$

4.0

$4 \cdot 1$ $1 \cdot 2$ 2.1 1.5

\section{The progress of infection}

Infection depends on chance contact between a root and a growing hypha, and there was no evidence that hyphae are attracted towards the root surface. Pregermination of the Endogone spores was essential but inoculum size had no obvious effect. Inoculation with a single germinated spore can lead to infection. Without the modifying influence of bacteria, or one of the substances listed, appressoria did not form. Hyphae then grew around and along the root surface without forming any firm attachment, until spore reserves were exhausted. Nevertheless, the seedling exerts some stimulatory effect, because without it growth of the germ tubes is limited, septa arise, and the protoplasm is retracted into the spore. Such spores, when suitably stimulated, can then germinate a second and third time. Under favourable conditions the first infections occur 5-10 days after inoculation, but the process may take 3 weeks or even longer. Penetration stimulates the growth of the infected root and of distal parts of the mycelial network. Hyphae grow beyond the cellophan disk and into the agar, and when they encounter another root establish 
further infections. Young infections are mainly in the form of arbuscules and of intercellular distributive hyphae, and are usually of limited extent. Root growth commonly outstrips the spread of the infection and, as in natural infections, the actively growing root tip is never invaded. Infections were rarely found in the main root, and there was no internal spread from one root to another. Usually less than a third of the total root system became infected. Anatomically, aseptically produced infections (PI. 1, fig. 1-5) are in every way comparable to those found in field plants. The first vesicles often occur close to a penetration point, indicating some association with more advanced stages of infection. As the infection progresses vesicles become more abundant, starch reserves disappear, and arbuscules break down till eventually no sign of them remains (Pl. 1, fig. 5). After 3-6 weeks test plants begin to decline and about this time the character of the Endogone infections undergoes a dramatic change. Coarse, macroscopically visible hyphae grow out from many parts of the infected root system (Pl. 2, fig. 6) and rapidly colonize the agar. Often such hyphae arise from prominent vesicles in the slowly disintegrating primary cortex. This observation supports the view of Schrader (1958) on the possible importance of vesicles as infective propagules. Anatomical evidence and the appearance of the plants suggest that, at this point, the relationship between plant and fungus changes to one of parasitism. In its growth the external mycelium resembles cultures of Rhizophagus sp. kindly supplied by Dr J. T. Barrett. The characteristic asexual spores produced by the external mycelium may eventually reach $75 \mu$ in diameter. In spite of its vigorous growth the mycelium could not be subcultured on hemp seed agar (on which the Rhizophagus grows) or on any other standard fungal medium.

\section{The maintenance of two-membered cultures}

Once a pure two-membered culture is established it can be propagated in several ways. Fresh seedlings can be planted on an infected agar slope that has been colonized by the Endogone mycelium, and new infections will develop in 5 to 10 days. The original mycorrhizal seedling nced not be present. Alternatively infected seedlings can be transplanted to fresh agar slopes which will in turn become colonized by hyphae arising from the infected root system, or pieces of infected roots can be used as inoculum. As, however, infected roots are distributed at random and are not easily recognizable without staining, the best way of selecting infective material is to plate out the entire root system in Jensen's medium and incubate the plates at $25^{\circ}$ for $36 \mathrm{hr}$. New hyphae arise from those parts of the root system that can be used successfully as inoculum. Where the infection is predominantly in the arbuscular stage no new hyphae arise; all such roots tested were non-infective. This agrees with the observations of Hawker et al. (1957), and supports the suggestion that the vesicular and arbuscular stages of an endotrophic infection may represent different phases in the balance between host and endophyte.

\section{The growoth of infected seedlings}

Mycorrhizal infection did not obviously improve the macroscopic appearance of test seedlings. Individual mycorrhizal roots, however, were often strikingly more vigorous than uninfected roots of the same seedling (PI. 2, fig. 7a, $b$ ). The length 
and number of branches of all first-order laterals were recorded in twenty seedlings selected at random from various successful inoculation experiments; in some, mycorrhizal infections had been established with the aid of a bacterial inoculum, in others with sterile filtrates. All the seedlings were showing signs of nitrogen starvation when they were harvested. Figure 1 shows the mean length of mycorrhizal and non-mycorrhizal roots. Only the first twenty-one laterals are included because in the more distal roots few mycorrhizal infections developed, probably because the inoculum was placed near the proximal end of the root system as indicated. Points near this position represent the oldest infections; those near the right-hand side of the diagram represent more recently infected roots. Second-order laterals were added to the length of the first-order lateral from which they arose. Seventynine $\%$ of mycorrhizal roots were longer than the mean of the nearest uninfected roots above and below them. Often they were two, three or even four times as

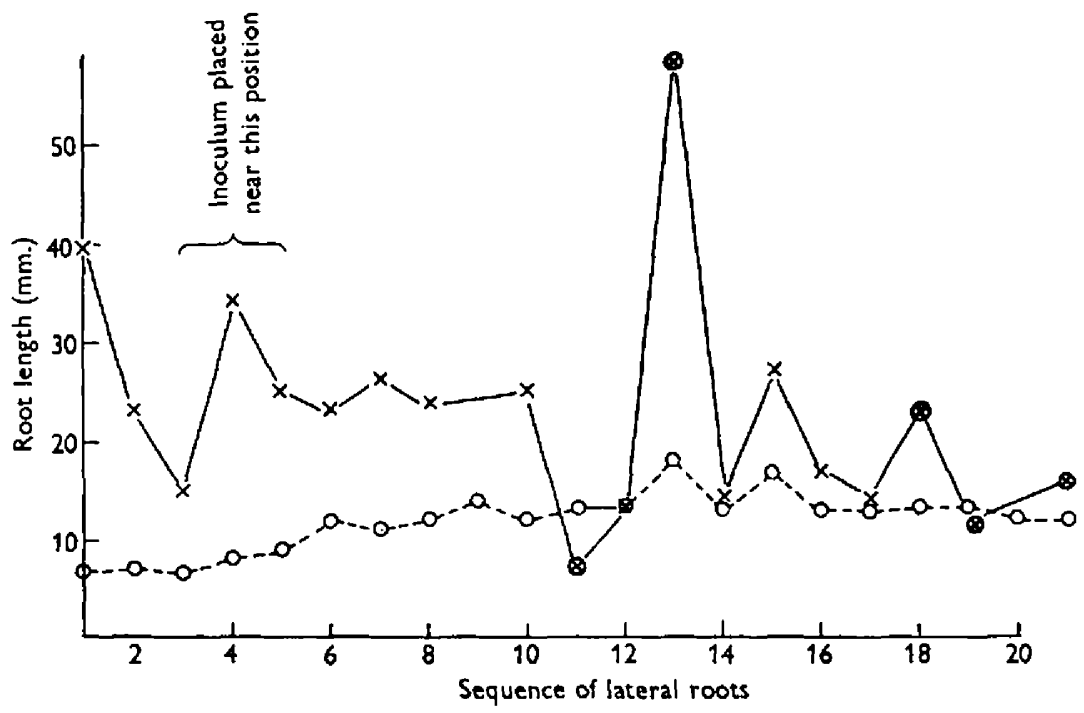

Fig. 1. Mean length of mycorrhizal and non-mycorrhizal first-order lateral roots in twenty seedlings of Trifolium parviflorum. 0 -... O, non-mycorrhizal roots; $x-x$, mycorrhizal roots; $\otimes$, point based on a single measurement.

long, and thus clearly outside the normal size range of uninfected roots. Mycorrhizal roots were also more profusely branched. There were thirty-three second-order laterals on a total of fifty-nine mycorrhizal roots, but only nine second-order laterals on 861 non-mycorrhizal ones.

The Pseudomonas inoculum used to establish mycorrhizal infections greatly improved plant growth and increased dry weight by up to $100 \% ; \mathrm{Pl} .2$, fig. 8 , shows typical seedlings. The mechanism of this effect was further investigated by chemical analysis and will be described elsewhere. For a better understanding of the conditions leading to mycorrhizal infections the following information is relevant. The bacterial inoculum benefits plant growth because the bacteria degrade nitrogencontaining impurities in the agar and thus make extra nitrogen available to the plant. Both pepsin and trypsin, and to a lesser extent Pectinol, had a similar effect on plant growth. The bacterial effect is therefore probably connected with the 
development of proteolytic enzymes in the bacteria. A range of soil saprophytic fungi also made extra nitrogen available to the seedling, as did the two mycorrhizal fungi Rhizophagus sp. and a strain of Pythium ultimum kindly supplied by Dr L. Hawker; but under the experimental conditions provided none of these fungi penetrated the clover roots. By contrast the extensive external mycelium developing from roots infected with Endogone did not excrt a similar proteolytic effect on agar nitrogen, for it did not noticeably improve plant growth. A non-nodulating strain of Khizobium sp. also had no effect on the availability of agar nitrogen.

\section{DISCUSSION}

The purpose of the inoculation experiments was to establish vesciular-arbuscular mycorrhiza under controlled microbiological conditions. Beneficial effects of such infections on plant growth have been reported by Mosse (1957), Peuss (1958), Bayliss (1959), Meloh (1961) and others; Meloh also recorded an increased uptake of dihydrostreptomycin. These results are open to the criticism that impure inocula were used to establish the infections, and that some or all of the observed effects were caused by other micro-organisms. This criticism does not apply to the present experiments in which a stimulatory effect of mycorrhizal infection on root growth was demonstrated under controlled microbiological conditions. Both root extension and branching were favourably affected. The possibility that mycorrhizal infection occurs in roots predisposed to, or already engaged in, vigorous growth is remote. Growth of the Endogone germ tubes is very limited and therefore the site of at least the first infections is determined, not by fungal selection, but almost entirely by the positioning of the inoculum. Although these observations establish that root growth can be stimulated by mycorrhizal infection, there is little indication how this occurs. The culture medium used in the inoculation experiments is very unbalanced, containing abundant phosphate and very little nitrogen, so that the latter almost certainly acts as a limiting factor in the later stages of seedling growth. Any improvements in growth therefore immediately suggest either an extra supply of nitrogen or a more efficient use of available sources. There were two possible sources of extra nitrogen in these experiments; i.e. nitrogenous impurities in the agar which were resistant to the proteolytic action of the Pseudomonas sp., or gaseous nitrogen in the atmosphere. Clearly if either of these sources were used, the amounts involved were small, because the stimulatory effects did not extend beyond the immediately affected roots. For this reason it would be desirable to improve culture techniques to obtain more abundantly infected root systems.

The main obstacle to more extensive infection is the inability of the Endogone sp. to infect aseptic seedlings, and lack of knowledge concerning the action of the bacterial inoculum and the sterile filtrates. Any satisfactory explanation must account for the following observations. (1) Infections occurred only under conditions of nitrogen starvation. The responsive units were probably the bacteria which developed proteolytic activity. No infections occurred when only plant and fungus were grown together under the same conditions. The mediating action of the bacteria is, however, unlikely to rest solely on the provision of proteolytic enzymes, because it could not be replaced by either pepsin or typsin. Neither docs it rest on some material in the agar, i.e. some trace element or amino acid, because infections 
were also produced in liquid culture without agar. The bacterial effect might depend on the destruction of some inhibitory substance present in the plant or the medium, but the destruction of such a hypothetical substance would have to be inhibited by soluble nitrogen. (2) Candle-filtered solutions of Pectinol, and of the liquid medium in which clover seedlings had been grown together with a Pseudomonas sp. had some ability to mediate Endogone infections, but induced fewer infections than the bacteria. (3) EDTA, autoclaved Pectinol and autoclaved culture filtrates sometimes mediated infections, and their activity could not depend on enzyme action.

The most likely explanation seems to be that the mediating substances act on the structure of the cell wall, modifying or dissolving its pectic components. This may be done by direct enzyme action involving pectolytic, proteolytic and possibly also cellullolytic enzymes, by removal through chelation of the calcium cross-linkages affecting both pectic and protein cell wall components (Wood, 1960; Ginzburg, 1961), or by altering the proportion of water-soluble to water-insoluble pectin, thus affecting cell wall plasticity. Increases in cell-wall plasticity have been reported as a result of treatment with autoclaved Pectinol (Jackson, 1959) and with growth substances (Albersheim \& Bonner, 1959; Jansen, Jang, Albersheim \& Bonner, 1960). Many of these withstand autoclaving. The proportion of water-soluble to water-insoluble pectin can also be affected by the availability of calcium and, as was shown by Edgington, Corden \& Dimond (1961), this can affect the susceptibility of plant tissue to fungal attack. Although resistance of the clover scedlings to infection may have been increased by the high calcium content of Jensens' medium, it is unlikely to have been entirely caused by it, because in earlier experiments (Mosse 1959a) other seedlings grown in tap water agar also resisted infection, indicating that the Endogone sp. genuinely lacks penetrating ability.

Vesicular-arbuscular endophytes have long been regarded as a group of highly specialized fungi. To the evidence of their great geological age, their high degree of adaptation to a restricted habitat and their near obligate relationship with a living host (which remains a characteristic attribute of most endophytes in spite of the artificial culture of two species) there can now be added, for the Endogone sp. used in the present experiments, a dependence on other soil micro-organisms for the processes of spore germination (Mosse, 1950a) and root penetration. The usual pattern is a dependence on root exudates for these two processes which are important stages in the establishment of fungal infections (Flentje, 1959).

The external mycelium which developed abundantly from Endogone-infected roots showed a remarkable similarity to cultures of Rhizophagus sp. The two fungi differ in their ability to grow on defined media, to break down nitrogenous impurities in the shredded agar, and to develop mycorrhizal infections under the conditions of the present experiments. In addition, infection with Endogone stimulated root growth under conditions where nitrogen was limiting growth. One is led to speculate whether the endophytic habit may be related to some special nitrogen requirement of the fungus. With a technique for producing mycorrhizal infections under controlled experimental conditions, this and other nutritional aspects of mycorrhizal infections can now be investigated.

I thank Dr P. S. Nutman and members of the Microbiology Department for their encouragement and for many helpful suggestions made in the course of this work. 


\section{REFERENCES}

Albersheim, P. \& Bonner, J. (1959). Metabolism and hormonal control of pectic substances. J. biol. Chem. 234, 3015.

BARRETT, J. T. (1947). Observations on the root endophyte Rhizophagus in culture. Phytopathology, 37, 359.

Barket, J. T. (1958). Synthesis of mycorrhiza with pure cultures of Rhizophagus, Phytopathology, 48, 391.

BakretT, J. T. (1959). Isolation, culture and host relation of the phycomycetoid vesiculararbuscular mycorrhizal endophyte Rhizophagus. Proc. 9th int. bot. Congr. 2, 1725.

Bayliss, G. T. S. (1959). Effect of vesicular-arbuscular myeorrhizas on growth of Griselinia littoralis (Cornaceae). New Phytol. 58, 274.

Edgington, L. V., Corden, M. E. \& Dimond, A. E. (1961). The role of pectic substances in chemically induced resistance to Fusarium wilt of tomato. Phytopathology, 51, 179 .

Fhmrafus, G. \& LuUnggren, H. (1959). The possible significance of pectic enzymes in root hair infection by nodule bacteria. Physiol. Plant. 12, 145.

Flentue, N. T. (1959). The physiology of penetration and infection. In Plant pathology problems and progress $1908-58$, ed. C. S. Holton and others. Madison, U.S.A.: University of Wisconsin Press.

Gerdemann, J. W. (1955). Relation of a large soil-borne spore to phycomycetous mycorrhizal infections. Mycologia, 47,619.

Ginzburg, B. Z. (1961). Evidence for a protein gel structure cross-linked by metal cations in the intercellular cement of plant tissuc. J. exp. Bot. 12, 85.

Hawker, L. E., Harrison, R. W., Nicholls, V. O. \& Ham, A. M. (1957). Studies on vesicular-arbuscular endophytes. I. A strain of Pythium ultimum Trow. in roots of Allium ursinum L. and other plants. Trans. Brit. mycol. Soc. 40, 375.

HEPoen, P. M. (1960). Studies in vesicular-arbuscular endophytes. II. Endophytes in the Pteridophyta, with special reference to Leptosporangiate ferns. Trans. Brit. mycol. Soc. 43, 55\%.

Humphies, E. C. \& Whefler, A. W. (1960). The effects of kinetin, gibberellic acid and light on the expansion and cell division in leaf dises of dwarf bean (Phaseolus vulgaris). J. exp. Bot. 11, 81.

JACKsoN, WM. T. (1959). The effects of pectinase and cellulase preparations on the growth and development of root hairs. Physiol. Plant. 12, 502.

Jansen, E. F., Jang, R., Albershrim, P. \& Bonner, J. (1960). Pectic metabolism of growing cell walls. Plant. Physiol. 35, 87.

JuNSEN, II. I. (1942). Nitrogen fixation in leguminous plants. II. Is symbiotic nitrogen fixation influenced by Azotobacter? Proc. Linn. Soc. N.S.W. 67, 205.

LJunggrfis, H. (1961). Ann. Rep. Rothamsted exp. Sta. p. 85.

MELoн, K. A. (1961). Untersuchungen zur Biologie und Bedeutung der endotrophen Mykorrhiza bei Zea mays $L$. und Avena sativa $L$. Dissertation der Universität Köln.

Mosse B. (1953). Fructifications associated with mycorrhizal strawberry roots. Nature, Lond. 171,974 .

Mosse, B. (1956). Fructifications of an Endogone sp. causing endotrophic mycorrhiza in fruit plants. Ann. Bot., Lond. 20, 349.

Mosse, B. (1957). Growth and chemical composition of mycorrhizal and non-mycorrhizal apples. Nature, Lond. 179, 922.

Mosse, B. $(1959 a)$. The regular germination of resting spores and some observations on the growth requirements of an Endogone sp. causing vesicular-arbuscular mycorrhiza. Trans. Brit. mycol. Soc. 42, 273.

Mosse, B. $(1959 b)$. Experimental techniques for obtaining a pure inoculum of an Endogone sp., and some observations on the vesicular-arbuscular infections caused by it. Proc. 9th int. bot. Congr. 2, 1728.

Nutman, P. S. (1949). Nuclear and cytoplasmic inheritance of resistance to infection by nodule bacteria in red clover. Heredity, 3, 263. 
Peuss, H. (1958). Ưntersuchungen zur Ókologie und Bedeutung der Tabakmycorrhiza. Arch. Mikrobiol. 29, 112.

Schraden, R. (1058). Untersuchungen zur Biologie der Erbsenmycorrhiza. Arch. Mikrobiol. 32, 81.

Tomlinson, J. A. \& WenB, M. J. W. (1960). Powdery mildew diseases. Rep. nat. veg. Res. Sta. Warwick, 10, 43.

Wood, R. K. S. (1055). Pectic enzymes secreted by pathogens and their role in plant infection. Symp. Soc. gen. Microbiol. 5, 263.

Woon, R. K. S. (1960). Pectic and cellulolytic enzymes in plant disease. Annu. Rev. Plant Physiol. 11, 299.

\section{EXPLANATION OF PLATES}

\section{Piate I}

Figs. 1-5. Vesicular-arbuscular infections in aseptically raised seedlings inoculated with sterile germinated spores of an kndogone sp. (L.S. root).

Fig. 1. Young infection, mainly arbuscular, in Trifolium pratense. Fungal penetration mediated by Pseudomonas sp. (isolate No. 1).

Fig. 2. Details of arbuscules in Trifolium parviflorum.

Fig. 3. Infection in Dactylis glemerata.

Fig. 4. Entry point and general infection in T. parvifiorum. Fungal penetration mediated by sterile filtrate from dual culture of $T$. parviflorum and Pseudomonas sp. (isolate No. 1 ).

Fig. 5. Four-months-old infection in $T$, parviforum. Prominent vesicles, absence of arbuscules and disintegrating cortex are typical of late infection stages when the seedling is nearly moribund.

Prate 2

Fig. 6. Root of $T$. parviflorum with vigorous emerging hyphae which remained attached to the infected root when it was pulled out of the agar medium.

Fig. 7. Aseptic seedlings of $T$. parviflorum grown in Jensen's medium and inoculated with sterile Endogone spores. Mycorthizal roots which are longer and more branched are marked $m \longrightarrow \rightarrow$ Fungal infection mediated by (a) Pectinol and (b) Pseudomonas sp. (isolate No. 1).

Fig. 8. Seedlings of $T$. parviflorum grown aseptically in Jensen's medium $(a)$ without and (b) with an inoculum of Pseudomonas sp. (isolate No. 1). 

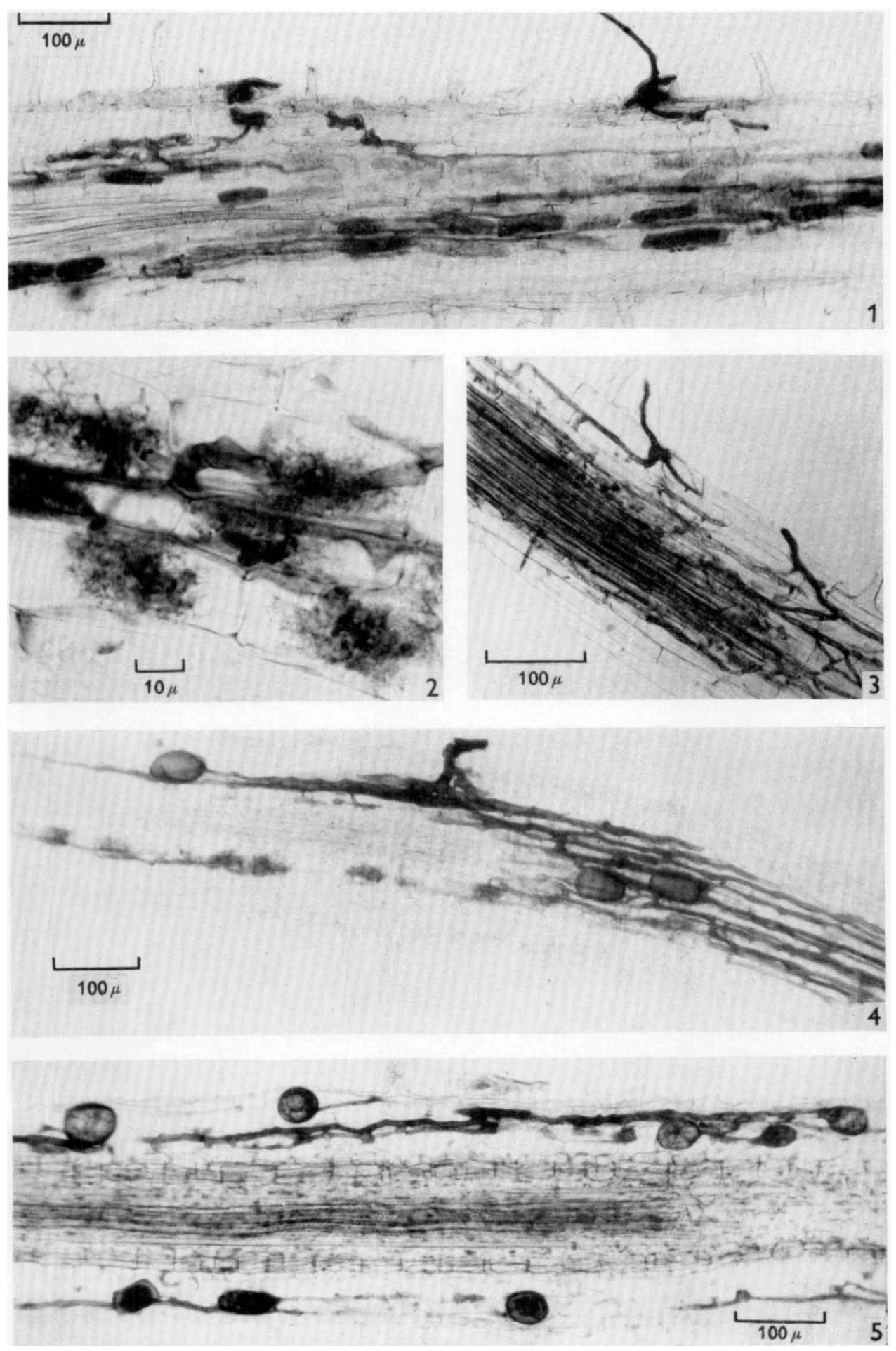

B. MIOSSE

(Facing p. 520) 
Journal of General Hicrobiology, Vol. 27, No. 3

Plate 2
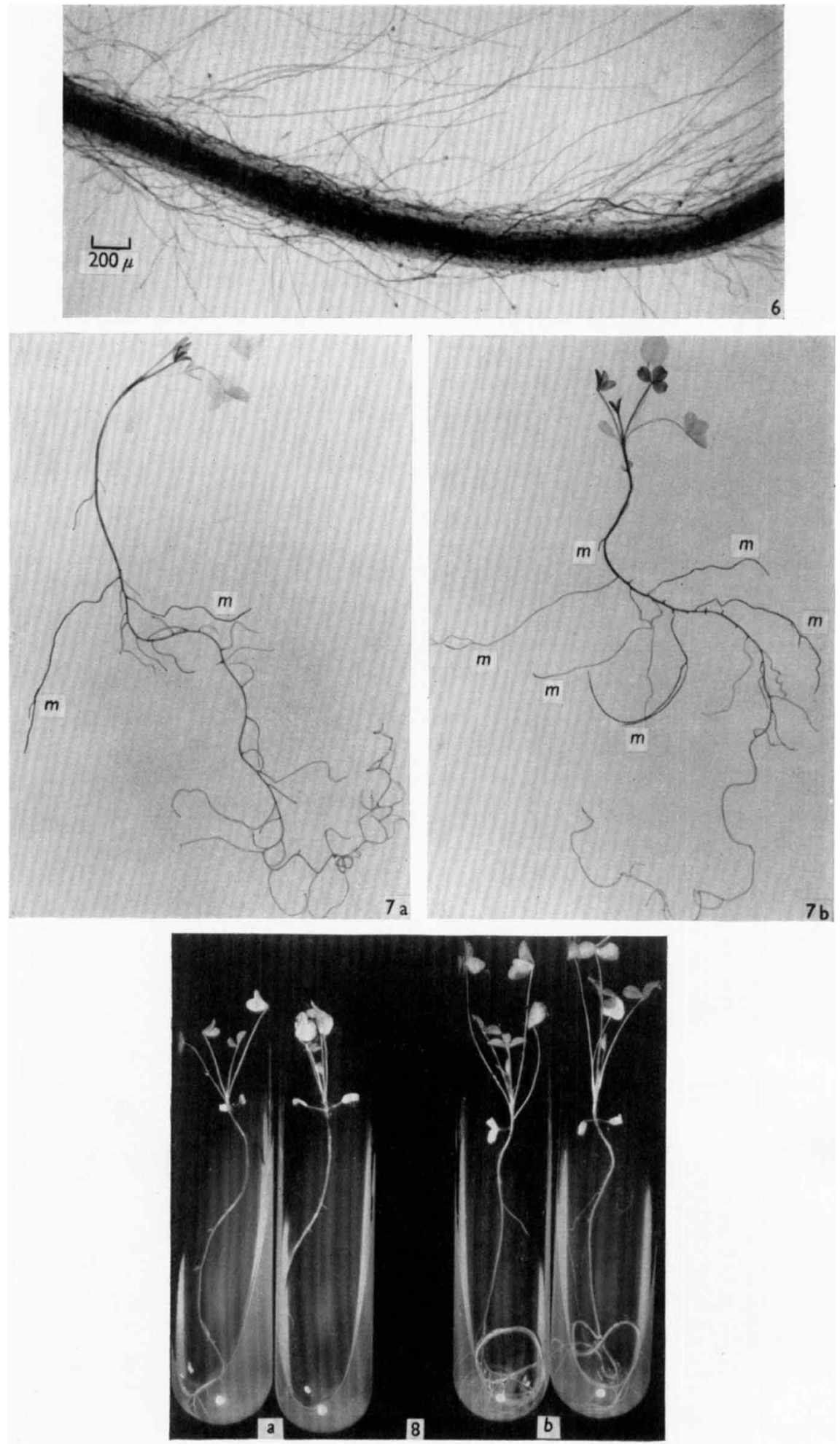

J3. Mosisl: 